\title{
Chapter 5 \\ Democratic Actions in School \\ Mathematics and the Dilemma of Conflicting Values
}

\author{
Annica Andersson and Lisa Österling
}

\begin{abstract}
This chapter reports and problematizes relationships between the expected democratic actions as part of the politically expected democratically inclusion of students' wishes and concerns; and students' valuing of mathematical activities in mathematics classrooms, departing from the Swedish results from a large-scale quantitative cross-cultural survey. We asked what are the conflicts between most valued activities by Swedish students and the valuing of democratic actions. The quantitative study showed that students value "knowing the times tables" and "teachers' explanations" and "correctness" over explorative, communicational and collaborative activities. We discuss the cultural and historical reasons behind these results and argue that we must understand the valuing of times tables or teachers' explanations as an expression of enculturated and therefore culturally valued actions in mathematics classrooms, where this enculturation takes place not only in school, but in conversations with parents, grandparents, in media and in children's books. We also argue that the conflict between the political expectations of democratic participation and actions, and the invitation to students to influence teaching on the one hand, and on the other hand students use of this influence through valuing teacher explaining, mastering times tables and understanding why the answer is incorrect, rather conserve a mathematics teaching organised around values as objectism and control than through openness and rationalism.
\end{abstract}

Keywords Democracy $\cdot$ Enculturation $\cdot$ Mathematical activities $\cdot$ Mathematics education · Students' valuing

\footnotetext{
A. Andersson ( $\square)$

University of South-Eastern Norway (USN), Post Office Box 4, 3199 Borre, Norway

e-mail: annica.andersson@usn.no

L. Österling

Stockholm University, Stockholm, Sweden

e-mail: lisa.osterling@mnd.su.se 


\subsection{Introduction}

This chapter reports and problematizes the relationships between the expected democratic actions and values in mathematics classrooms, departing from the Swedish results from the large-scale quantitative cross-cultural survey, 'What I Find Important (in mathematics learning)' [WIFI]. It surveys students' valuing of different mathematics learning activities and their importance for students' learning across cultures. Initially, two main reasons made us use the WIFI questionnaire. First, we wanted to learn about what Swedish students value when participating in mathematical activities, with a possible further goal to understand cultural similarities and differences from the comparisons of results from the participating 19 countries. This will be briefly discussed and problematised as the survey results are the background for this study. The second reason was to further understand students' valuing, as part of the politically expected democratically inclusion of students' wishes and concerns in the planning of mathematics classroom activities (Ministry of Education 2011). The latter reason is the foregrounded focus of this chapter.

In this chapter, we first give a theoretical and contextual research background. We then present the survey and discuss its validity before accounting for the results of the 748 eleven- and fifteen-year-old students' survey responses. Thereafter, based on these results, we address the challenges teachers may experience when working towards a politically expected democratic inclusion in mathematics education. In doing so, we take our departure with the assumption that teaching, as well as students' valuing of mathematical classroom activities is, of course, not only influenced by the recent curriculum. It is also influenced by ideologies and epistemologies of the learning of mathematics, as well as contextual and societal cultures and traditions.

\subsection{Theoretical Framework}

\subsubsection{Mathematical Values and Democracy}

The idea that Mathematics is a neutral and objective area of knowledge is challenged in research (c.f. Biesta 2009; Skovsmose 2005). For example, the historical but also recent changes in Japanese school mathematics illustrate how different aspects of mathematics has been both valued by, and depending on, societal and political changes (Baba et al. 2012). The work of Alan Bishop provided an important contribution to the understanding of values in mathematics. He defined mathematics learning as an enculturation process where students are expected to enter and become part of mathematics communities and thereby enculturate values of mathematics and mathematics education. In this process, teachers and students "do not have equal roles to play, nor do they meet on equal terms" (Bishop 1988). A legitimate use of teachers' power can, according to Bishop (2002), be the specific fostering of mathematical values in order to enculturate students into the culture of a mathematical commu- 
nity. This process might involve a shift of students' values; from the cultural values students bring to school, to the appreciated mathematical values necessary for the entrance to the mathematical community.

We here emphasise that we resonate with Hofstede et al. (2010) definition of values as shared by members of a community. Such values will not only be shared, but also part of determining who is a community member or who is not, since social conventions as well as laws are based on shared community values. Those values might or might not be recognized by the members of such communities, but value-differences from other communities may be easily recognized. Thereby, in this chapter we understand values as guiding our valuing of what is important to students and teachers (and researchers) or not, what is good or bad, what is beautiful or ugly, and so on. In order to choose to engage in purposeful learning, students and teachers in mathematics classrooms need to share some basic values of mathematics and mathematics education. In addition, we add, that to make students' democratic actions possible, spaces for conversations, negotiations and expressing views on and with mathematics and mathematical knowledge need to be available and negotiable in mathematics classrooms.

The basic general values that give political educational directions for teachers in Swedish schools are based on societal values as "fundamental democratic values" and "human rights" (Ministry of Education 2011, §4, 5). These notions grant students a large amount of influence on their education and also a responsibility, as being part of civil democratic obligations. Here are two examples from the national steering documents we refer to:

\section{Teachers shall:}

Be responsible for ensuring that all pupils can exercise real influence over working methods, forms and contents of education, and ensure that this influence grows with increasing age and maturity.

I.../

Prepare pupils for participating and taking responsibility, and applying the rights and obligations that characterise a democratic society (Skolverket 2011, p. 17, Skolverket's translation).

These paragraphs shall be taken into account in all subject areas, and are therefore not explicitly repeated in the mathematics part of the curriculum. Democratic participation is not to be understood as democratic education per se nor creating democratic citizens or individuals through teaching about democracy. Actually, the word "democracy" is not explicitly defined in the Swedish curriculum. Instead, it is based on values as explained in the very first paragraph:

The Education Act (2010:800) stipulates that education in the school system aims at pupils acquiring and developing knowledge and values. [...] Education should impart and establish respect for human rights and the fundamental democratic values on which Swedish society is based. Each and everyone working in the school should also encourage respect for the intrinsic value of each person and the environment we all share (Skolverket 2011, p. 9, our italics).

In an OECD report from 2006, we read that teachers should be "providing equal opportunity for all children within a universal system in which values of citizenship 
are inculcated, and a democratic and multicultural mixing of children is practiced" (p. 118) and specifically for the Nordic tradition focusing on democracy: "Centre goals are to support child development and learning and provide experience of democratic values" (p. 143). What these "democratic values" explicitly means is again not clear. However, researchers in educational values in early childhood education, points out that the values in Nordic countries may differ amongst each other. For example, Alvestad and Samuelsson (1999) showed that when the Norwegian curriculum was built upon a Christian orientation, the Swedish was built upon a more democratic perspective. A textual analysis of Nordic preschool curricula showed that

In the Danish, Icelandic, Norwegian and Swedish curriculum frameworks, democracy is explicitly defined as one of the fundamental pillars that the guidelines are based on, and thus, the term is used frequently throughout the documents. The Finnish curriculum guidelines are unique in that they do not use the term democracy. However, basic notions of democracy, such as children's participation and influence, are stressed in all the documents and form a foundation for pedagogical practice (Einarsdottir et al. 2015, p. 102).

As an alternative to "democratic participation" we rather bring the idea of democratic actions (Biesta 2007) forward. Biesta argues that individuals, through actions as an alternative to participating in democratic education as a school subject, "become subjects in the routines of everyday [school] life". Hence students' experience of democracy is "lived", "becomes real" and thus "make [democratic] action possible" (p. 761).

In other words, our understanding of the political intentions formulated in the Swedish curriculum of "democratic participation", "inclusion", or as we prefer, "democratic action" (Biesta 2007) is that students shall experience opportunities to firstly, actively participate in planning, working and assessing activities in the mathematics classroom, and secondly, to participate in mathematical activities that to some extent are exploratory and open for collaborations, conversations and contributions of all participants on equitable premises.

\subsubsection{Students'Democratic Participation in Mathematics}

In a global context, the United Nations (2016) recognises democracy as one of its core values and ideologies. The quotes above from the Swedish steering document demonstrate that Swedish schools are not value-neutral. Swedish education aims to reinforce rights and obligations that characterise a democratic society. Thus, democracy here is connected to values as the means and purpose of democracy in line with the United Nations Declarations (2016) as to realize human rights.

These perspectives touch on many areas in mathematics education, from the shared responsibility for learning, over intertwinedness of human relations in the participation in mathematics work, and finally the power to decide what counts as mathematical knowledge. An extended literature review of research about democracy and mathematics education highlights the tensions within this relationship and concludes that "indeed there are connections between mathematics education and democracy, 
[...] However, these connections are not always positive. Mathematics education can promote democratic competences and values, but it can also inhibit them, and create social inequalities" (Aguilar and Zavaleta 2012, p. 10)

From a student's perspective, Zizzi's, the democratic action as shared responsibility seems to be a new and strange experience in school mathematics.

This was really meaningful and it was good to take personal responsibility for planning and for our own labour. But this is new; we have to practice this way of working. (Andersson and Valero 2015, p. 212)

Zizzi, 15, shared this comment on the classroom blog after working in a group in a mathematical project that was constructed with the aim of allocating students' responsibilities for planning and assessing the project while pursuing their mathematical knowledge. She acknowledged the mathematical goals of the project, and the responsibilities that came with this way of working. However, she pointed out that this was a new way for her to work in a mathematics classroom. Her previous experiences consisted of individual textbook work, and this comment alerted the teacher to realise that democratic or collaborative ways of working in mathematics needed to be learnt, if a shared responsibility between teachers and students should be attained in the mathematics classroom.

The fact that basic general democratic values give directions for teachers impose that Swedish schools grant students a large amount of influence on their education. However, several research examples demonstrate how challenging it may be to combine with mathematics learning. As part of a modelling research project in upper secondary schools, Lingefjärd and Meier (2010) analysed a classroom-vignette where a group of students wants to further question and discuss their developed advanced formula with their teacher, who responds: "Well, if it is your formula, then go ahead and explain it!" (p. 103). When the researchers ask further about this interaction, the teacher refers to the mathematics curriculum, which with this teacher's words stated that students should 'learn to work on their own'. However, what this episode shows are that despite the teacher's good intentions of granting students influence, the lack of framing resulted in these students neither learned mathematics nor learned to work independently.

In addition, Johansson (2006) described how, in the name of democratic participation, the responsibility for learning is often passed on from teachers to students and even to the textbooks. Especially students with Swedish as their second language are found to be disadvantaged in this type of teaching. Thus, instead of improving inclusion in mathematics education, this way of making students 'responsible' for their learning widens the gap between students who are familiar with the expectations and discourses within the mathematics educational culture, and students who do not have access to the discourses (Hansson 2010). Teachers, in the name of allocating influence and responsibility, instead engage in a form of individualized or studentcentred learning, a practice where teachers are seen too often abandon students who need guidance and instead expect students to work on their own with textbooks tasks and problems (Johansson 2006; School Inspectorate 2009, 2010). In contrast, Norén (2015) demonstrates how teachers allowed second language learners taking 
control of their learning by using their previous experiences, and thus allowed them to become more engaged in mathematical activities. Here, the inclusion of learners was facilitated by adaptation to students' experiences.

To invite students to engage in a teaching based on democratic actions often includes collaborations not only with the teacher, but also with peers. Thus, human relations in group work becomes intertwined with the learning of mathematics. Kurth et al. (2002) reminds us that students might be unsuccessful due to their obligations both to the working group and to the learning of mathematics. These two aspects also occur when Wood (2013) describes grade four students' different positionings in mathematics group work (as experts, novices or facilitators) demonstrates the complexity of collaborative work. Esmonde (2009) showed a range of different work practices were individual students adopted these positions in three secondary classrooms over a year. The mathematical interactions were mainly dominated by the "experts" whereas "interactions were more equitable particularly when a student was positioned as a facilitator" (p. 247). As we interpret Esmonde's findings, more democratic actions might take place when a facilitator is positioned within mathematical working groups. Andersson and Wagner (2017) alert us through a SFL analysis how mathematical conversations underpin both "love" and "bullying" in students' interactions. In addition, DeJarnette and González (2015) show how mathematical reasoning and students' positionings in groups are intertwined, hence a democratically inclusion may depend on individual students' mathematical knowledge. In other words, some students may be more active in mathematical reasoning than others, who might be quieter. We add that democratic actions also call on aspects as listening and talking space. Thus, equitable premises are required in mathematical collaborative activities when aiming for democratic inclusion.

On the other hand, students' possibilities for achieving influence and acting in more democratic ways may be facilitated if students understand and agree on the stated mathematical and task objectives (Andersson 2011) or align with the prevailing values in the mathematical classroom (Seah and Andersson 2015; Swan 2014). The reasons for this might be explained by Wagner and Herbel-Eisenmann (2009, 2014). They make the distinction between students' personal authority, and the disciplinary authority of mathematics. The authority of mathematics might not lend itself to negotiation. Stemhagen (2016) argues, through using Dewey's ideas, where democratic participation and actions consists of mathematics linked to children's lived inquiries, that "deep and unresolved tensions in the philosophy of mathematics and the philosophy of education have made it difficult for promising [democratic] pedagogies to be enacted" (p. 95).

Nevertheless, democratic participation and actions, inclusion and collaborative work are politically expected virtues in mathematics education today, at least in Sweden, and hence require our research attention. From this overview, we conclude that an active participation of students, in the name of participation, positioning, authority, agency, activity or collaboration, is related to a democratic classroom. We also see how such classrooms might be specifically challenging for mathematics teachers to establish, or, as Bishop (1988) would put it, to enculturate democratic values. We remind ourselves about 15-year old Zizzi's comment, that organising 
mathematical activities democratically might need to be "practiced", or at the least negotiated between teachers and students.

\subsection{Purpose and Research Questions}

The purpose of this chapter is first, to understand what values students perceive as important in the Swedish mathematics classroom and second, to understand how students' valuing are in line with or opposed to values of democratic participation and actions. We relate to two guiding questions:

1. How important are different mathematics classroom activities, specifically those related to democratic actions, for Swedish students in their mathematics learning?

2. What are the conflicts between most valued activities by Swedish students and the valuing of democratic actions?

In other words, we explored whether if there is harmony, tension or a conflict between students' valuing of mathematical activities for learning mathematics and the politically desired democratic values in Swedish mathematics classrooms.

\subsection{Methodology}

\subsubsection{The Survey Instrument}

The WIFI study ${ }^{1}$ was originally developed in English in an Australian-Asian context with the intention to learn more about what students' value when learning mathematics at school. This was obtained through a quantitative cross-cultural survey that investigated students' values through grading the importance of mathematical activities in more than twenty world-wide countries. However, children responding to the questionnaire cannot be expected to relate directly to a value; for example, it is difficult for students to understand or to answer the question "How important is rationalism when learning mathematics?" The participating students were instead asked to value 64 items describing various mathematical learning activities, by marking their importance for learning mathematics on a scale, from absolutely unimportant to absolutely important. In the WIFI-study, the intentions were to focus and compare as many activities as possible, to analyse these activities connectedness to certain mathematical values, and then compare the results between countries or cultures.

As we were conducting research in a Swedish language and context, we needed to address linguistic and cultural challenges at different stages of the project to be able to make cross cultural comparisons (Andersson and Österling 2014). A team of three researchers were engaged in a series of three adjugation meetings for such

\footnotetext{
${ }^{1}$ The survey is available at https://melbourneuni.au1.qualtrics.com/jfe/form/SV_7PaiTvst3sSflrL.
} 
adaptation process, where the first meeting engaged the translated and back-translated questionnaire, the second the results from the piloted version, and the final third meeting developed the final version.

When we translated and adopted the questionnaire we followed the Survey Research Centre's (2010) "Guidelines for best practice in Cross-Cultural surveys". These guidelines state that translation and back translation processes are not sufficient, hence a cultural adaptation was necessary. Thus, direct translations are not always sufficient. Instead, adaptations to guide comprehension, improve conceptual coverage and a cultural sensitivity of what is appropriate are recommended. Therefore, we engaged a pilot-test, where 28 Swedish students of the targeted agegroup were selected for interviews on their interpretation of difficult items. As an example, the English source questionnaire asked students to value the importance of "Mathematics debates". In the 1st translation, this was translated to "Debatter med matematik", and the back translation was close enough, "debating maths". However, when trying out the questionnaire in the pilot test, one out of three students did not understand the question. And when discussing "Mathematics debates" in the 2nd adjudication, not even the participating adjudicators were sure about how such a debate is enacted in the classroom. "Mathematics debates" are in the WiFi Research Guidelines (not published) classified as an indicator of valuing openness and exploration. Mathematics debates is not a common name of such activities in Swedish classrooms, so out of what it is supposed to indicate, we tried to adapt the indicator, and describe an activity that children could recognise. In the 2 nd translation, the question was formulated "Debattera och ifrågasätta lösningar i matematik" (Debate and question mathematical solutions). This was made to improve the comprehension, by providing an example Swedish learners would comprehend, but which would still be an indicator of students valuing openness and exploration.

Secondly, we introduced a similar format for all items. We checked that each item consisted of a verb together with an object; for example, the item "Investigations" became in the Swedish version formulated as "Making investigations" (for further methodological discussions on the translation and adaptation process see Andersson and Österling 2013, 2014).

\subsubsection{Survey Sample and Data Collection}

Our aim was to achieve a spread of students from public as well as private schools, rural as well as urban areas, and a geographical distribution over Sweden. We needed to find mathematics teachers who would be interested in participating, in order to get access to students as respondents. We did not have access to a database of students nor mathematics teachers to be able to plan a random probability sample. Instead, we wanted to achieve a quota sampling, with equal numbers of the both age groups, boys and girls and a geographic spread. To get access to students, we used a convenience sampling through contacting mathematics teachers who previously had been participating in a national mathematics project. These geographically well spread 
teachers helped us distribute the survey. We analysed respondents to check the relative proportions between the years five and eight students to be approximately equal, and for the distribution of gender, and we achieved a fair distribution.

The participating teachers received a letter of instruction with information regarding the Swedish ethical guidelines (Swedish Research Council 2011) together with the web link. The web-survey was distributed and collected by Survey and Report software. We received 850 completed survey forms. Before beginning the statistical analysis, we removed respondents with more than $10 \%$ answers missing, which left 742 students' responses.

\subsubsection{Analysing Democratic Actions Through Values Behind Survey Items}

To be able to tease out the relationship between the students' appreciated activities and hence valuing in mathematics classrooms and the values stated as democratic actions in the national steering documents in mathematics, we turn to the enculturation of mathematical values in schools (Bishop 1988; Seah 2013), which are briefly described in Table 5.1.2

In each of the three dimensions, a pair of opposing values are described. This can be understood as two opposing positions, and in a certain community or mathematics classroom, values are understood to be positioned somewhere on a continuum between the extreme values. In the ideological dimension, rationalism allows for students to communicate and argue for a solution or line of reasoning in mathematics. This reason with the idea of participation as an agentic activity, and ideas about sharing and understanding the arguments of others. The value of objectism instead focuses application of pre-determined formulae and praxis of symbolising.

Table 5.1 Mathematical values (see Bishop 1988)

\begin{tabular}{l|l|l}
\hline Dimension & Pairs of opposing values \\
\hline $\begin{array}{l}\text { Ideological values: the } \\
\text { ideology of mathematics }\end{array}$ & $\begin{array}{l}\text { Rationalism-reasoning and } \\
\text { argument is valued }\end{array}$ & $\begin{array}{l}\text { Objectism-symbolising and } \\
\text { applying ideas of } \\
\text { mathematics is valued }\end{array}$ \\
\hline $\begin{array}{l}\text { Sociological values: who can } \\
\text { do mathematics }\end{array}$ & $\begin{array}{l}\text { Openness-mathematics is } \\
\text { democratically open for } \\
\text { anyone to use and explain }\end{array}$ & $\begin{array}{l}\text { Mystery - the mystique of } \\
\text { mathematical ideas and their } \\
\text { origin and who possesses the } \\
\text { power to explore }\end{array}$ \\
\hline $\begin{array}{l}\text { Sentimental values: What } \\
\text { sensations mathematics can } \\
\text { bring }\end{array}$ & $\begin{array}{l}\text { Control-a sense of certainty } \\
\text { and power through mastery } \\
\text { of rules is valued }\end{array}$ & $\begin{array}{l}\text { Progress - the sense of ideas } \\
\text { growing through questioning } \\
\text { is valued }\end{array}$ \\
\hline
\end{tabular}

\footnotetext{
${ }^{2}$ Bishop (1988) also cautioned that these six values are discussed in the context only of Western mathematics classrooms.
} 
Table 5.2 Items associated with values of openness, progress or rationalism

\begin{tabular}{l|l}
\hline Value & Questionnaire item \\
\hline \multirow{4}{*}{ Openness } & Small-group discussions \\
\cline { 2 - 2 } & Whole-class discussion \\
\cline { 2 - 2 } & Debates \\
\cline { 2 - 2 } & Explaining where formulae or rules came from \\
\hline \multirow{4}{*}{ Progress } & Relating maths to other subjects \\
\cline { 2 - 2 } & Stories about recent developments in maths \\
\cline { 2 - 2 } & Relationships between concepts \\
\hline & Abstract or theoretical aspects of maths \\
\cline { 2 - 2 } & Learning the proofs \\
\cline { 2 - 2 } & Verifying theorems or hypotheses \\
\cline { 2 - 2 } & Learning the proofs \\
\cline { 2 - 2 } & Verifying theorems or hypotheses \\
\hline
\end{tabular}

In the sociological dimension, openness is the idea of mathematics being open for inquiry and explanations, thus a description of activities that invite students to actively participate. In activities related to mystery, mathematical ideas are usually already outlined and described by someone else (c.f. Andersson and Wagner 2018). In the sentimental dimension, progress relates to activities where students have the sense of having the opportunity to develop own ideas through questioning and exploring. Control instead describes activities that reinforce the sense of correctness, mastery and certainty (Bishop 1988, 2002).

The most evident values to be connected to democratic actions are found in the sociological dimension, where openness, described as mathematics being open to everybody to explain, reasons with our description of democratic participation as having opportunity to actively contribute to mathematical work on equal terms.

In the other dimensions, progress, allowing ideas to grow through questioning rhymes with the description of democratic participation as exploring, collaborating and communicating. Also, the value of reasoning aligns with the ideas of actively communicating mathematical ideas. Therefore, in this chapter, we argue that the valuing of rationalism, openness and progress are strongly related to democratic actions in mathematics classrooms (see also Seah et al. 2016). The WiFi-questionnaire had associated research guidelines which suggested how the items in the questionnaire were distributed among mathematical and mathematics educational values. In those guidelines, the items associated with openness, progress and rationalism are shown in Table 5.2.

The items above are examples of activities in mathematics classroom. Thus, this distribution was our starting point for investigating which democratic actions students valued as important in Swedish mathematics classrooms. 


\subsubsection{Methods of Statistical Analysis}

We conducted a descriptive analysis in SPSS where we calculated means and standard deviations with the aims to find what students value as important or not important among the 64 items in the survey: 1 corresponded to the valuing of absolutely important, 5 corresponded to absolutely unimportant, and 3 corresponded to a neutral alternative.

The initial plan was to use a principal component analysis (PCA) to see whether such components could be interpreted in terms of mathematical values. However, despite different analytical approaches, the resulting components would consist of one large component containing more than a third of the items, and the remaining components did not relate to values. Instead we saw how they consisted of similar activities, as valuing ICT in different forms. Thus, we could not find the hypothesized distribution of research items related to values in accordance with the research guidelines, as described in the previous section. In addition, since our sample was a non-probability sample, we did not have the statistical means for estimating errors. Despite these shortcomings, we did see some patterns in the responses.

As described above, in a classroom aiming for democratic actions; rationalism, openness and progress would be the desired values. Being cautions not to extend beyond the reliability of the sampling or analytical methods, we will present the descriptive statistics, and compare the most and least valued items.

\subsection{Results}

In this results section, we first present the means and standard deviations of all items, sorted from the most valued to the least valued (Table 5.1). This result is used to describe the importance students attribute to items connected to democracy, in relation to the other items. Thereafter, we focus the most and least valued items, to see what it is students do value.

\subsubsection{Results for All Items}

Table 5.3 shows the means and standard deviations for all 64 items.

It will be noticed first; the means indicate that no item is valued as not important, including items related to democratic actions. Second, the standard deviations demonstrate that the spread is small among the most valued items and larger among the least valued items. A larger deviation for items with means at the middle of the Likert-scale is not unexpected, since it deviates to both sides. 
Table 5.3 Descriptive statistics of responses to the WIFI-questionnaire ( $\mathrm{N}$ is the number of returns per item)

\begin{tabular}{|c|c|c|c|}
\hline Items ranked from most valued & $\mathrm{N}$ & Mean & $\begin{array}{l}\text { Std. Dev. } \\
(\sigma)\end{array}$ \\
\hline 1. Explaining by the teacher & 742 & 1.33 & 0.700 \\
\hline 2. Knowing the times tables & 742 & 1.43 & 0.767 \\
\hline 3. Understanding why my solution is incorrect or correct & 736 & 1.45 & 0.708 \\
\hline 4. Learning through mistakes & 743 & 1.54 & 0.781 \\
\hline 5. Remembering the work we have done & 737 & 1.57 & 0.805 \\
\hline 6. Understanding concepts/processes & 738 & 1.57 & 0.756 \\
\hline 7. Alternative solutions & 739 & 1.59 & 0.841 \\
\hline 8. Examples to help me understand & 743 & 1.64 & 0.778 \\
\hline 9. Teacher helping me individually & 745 & 1.69 & 0.818 \\
\hline 10. Knowing the steps of the solution & 736 & 1.70 & 0.799 \\
\hline 11. Looking for different ways to find the answer & 741 & 1.70 & 0.805 \\
\hline 12. Knowing which formula to use & 732 & 1.70 & 0.797 \\
\hline 13. Working step-by-step & 740 & 1.71 & 0.841 \\
\hline 14. Memorising facts & 741 & 1.72 & 0.849 \\
\hline 15. Me asking questions & 738 & 1.73 & 0.870 \\
\hline 16. Problem-solving & 736 & 1.74 & 0.793 \\
\hline 17. Completing mathematics work & 737 & 1.75 & 0.843 \\
\hline 18. Given a formula to use & 741 & 1.75 & 0.843 \\
\hline 19. Shortcuts to solving a problem & 737 & 1.78 & 0.876 \\
\hline 20. Feedback from my teacher & 741 & 1.79 & 0.865 \\
\hline 21. Practicing how to use maths formulae & 742 & 1.79 & 0.901 \\
\hline 22. Connecting maths to real life & 740 & 1.81 & 0.868 \\
\hline 23. Verifying theorems and hypotheses & 742 & 1.83 & 0.841 \\
\hline 24. Knowing the theoretical aspects of mathematics & 734 & 1.85 & 0.876 \\
\hline 25. Getting the right answer & 737 & 1.86 & 1.006 \\
\hline 26. Writing the solutions step-by-step & 743 & 1.86 & 0.871 \\
\hline 27. Mathematics tests/examinations & 739 & 1.89 & 0.997 \\
\hline 28. Looking for different possible answers & 744 & 1.90 & 0.820 \\
\hline 29. Teacher asking us questions & 740 & 1.96 & 0.912 \\
\hline 30. Mystery of maths & 732 & 1.96 & 0.904 \\
\hline 31. Relationships between maths concepts & 742 & 1.96 & 0.795 \\
\hline 32. Using mathematical words & 742 & 1.97 & 0.937 \\
\hline 33. Learning the proofs & 736 & 1.98 & 0.938 \\
\hline 34. Practicing with lots of questions & 741 & 1.99 & 0.920 \\
\hline
\end{tabular}


Table 5.3 (continued)

\begin{tabular}{l|l|l|l}
\hline Items ranked from most valued & N & Mean & $\begin{array}{l}\text { Std. Dev. } \\
(\sigma)\end{array}$ \\
\hline 35. Working on the maths by myself & 737 & 1.99 & 0.912 \\
\hline 36. Mathematics puzzles & 738 & 2.00 & 0.924 \\
\hline 37. Hands-on activities & 739 & 2.01 & 0.961 \\
\hline 38. Looking for maths in real life & 743 & 2.06 & 0.919 \\
\hline 39. Mathematics debates & 736 & 2.07 & 0.922 \\
\hline 40. Using diagrams to understand maths & 740 & 2.08 & 0.870 \\
\hline 41. Using concrete materials to understand mathematics & 735 & 2.09 & 0.868 \\
\hline 42. Teacher use of keywords & 739 & 2.11 & 0.934 \\
\hline 43. Explaining where rules/formulae came from & 738 & 2.12 & 0.940 \\
\hline 44. Stories about recent developments in mathematics & 742 & 2.16 & 0.997 \\
\hline 45. Doing a lot of mathematics work & 738 & 2.18 & 1.022 \\
\hline 46. Mathematics homework & 736 & 2.20 & 1.242 \\
\hline 47. Relating mathematics to other subjects in school & 740 & 2.22 & 0.980 \\
\hline 48. Investigations & 737 & 2.22 & 0.865 \\
\hline 49. Small-group discussion & 738 & 2.26 & 0.919 \\
\hline 50. Whole-class discussion & 737 & 2.29 & 0.979 \\
\hline 51. Mathematics games & 741 & 2.29 & 1.028 \\
\hline 52. Explaining my solution to the class & 737 & 2.33 & 1.146 \\
\hline 53. Making up my own math questions & 738 & 2.39 & 1.046 \\
\hline 54. Feedback from my friends & 741 & 2.41 & 1.089 \\
\hline 55. Students posing maths problems & 741 & 2.45 & 0.935 \\
\hline 56. Using the calculator to check the answer & 741 & 2.46 & 1.084 \\
\hline 57. Learning with the internet & 741 & 2.47 & 1.062 \\
\hline 58. Learning with the computer & 741 & 2.51 & 1.056 \\
\hline 59. Outdoor mathematics activities & 743 & 2.52 & 1.157 \\
\hline 60. Using the calculator & 738 & 2.54 & 1.059 \\
\hline 61. Appreciating the beauty of maths & 744 & 2.54 & 1.059 \\
\hline 62. Stories about mathematics & 737 & 2.64 & 1.128 \\
\hline 63. Stories about mathematicians & 737 & 2.74 & 1.137 \\
\hline 64. Being lucky at getting the correct answer & 2.75 & 1.212 \\
\hline
\end{tabular}


Table 5.4 Results related to openness, progress or rationalism

\begin{tabular}{l|l|l|l|l}
\hline Value & Item & Rank & Mean & Std \\
\hline \multirow{2}{*}{ Openness } & Small-group discussions & 49 & 2.26 & 0.919 \\
\cline { 2 - 5 } & Whole-class discussion & 50 & 2.29 & 0.979 \\
\cline { 2 - 5 } & Debates & 39 & 2.07 & 0.922 \\
\cline { 2 - 5 } & $\begin{array}{l}\text { Explaining where } \\
\text { formulae or rules came } \\
\text { from }\end{array}$ & 43 & 2.12 & 0.940 \\
\hline Progress & $\begin{array}{l}\text { Relating maths to other } \\
\text { subjects }\end{array}$ & 47 & 2.22 & 0.980 \\
\cline { 2 - 5 } & $\begin{array}{l}\text { Stories about recent } \\
\text { developments in maths }\end{array}$ & 44 & 2.16 & 0.997 \\
\cline { 2 - 5 } & $\begin{array}{l}\text { Relationships between } \\
\text { concepts }\end{array}$ & 31 & 1.96 & 0.795 \\
\hline \multirow{2}{*}{ Rationalism } & $\begin{array}{l}\text { Knowing the theoretical } \\
\text { aspects of maths }\end{array}$ & 24 & 1.85 & 0.876 \\
\cline { 2 - 5 } & Learning the proofs & 33 & 1.98 & 0.938 \\
\cline { 2 - 5 } & $\begin{array}{l}\text { Verifying theorems or } \\
\text { hypotheses }\end{array}$ & 23 & 1.83 & 0.841 \\
\hline
\end{tabular}

\subsubsection{Items Associated with Democratic Actions}

From Table 5.3, we assemble the items associated with democratic actions through the valuing of openness, progress and rationalism and show the results in Table 5.4.

From this list of results, we can conclude that the items related to democratic actions are neither the most, or the least valued activities by the students. Among the three value dimensions, rationalism seems valued as slightly more important compared to progress or openness.

\subsubsection{The Most or Least Valued Activities}

The distribution of responses for the most valued items are shown in Fig. 5.1, together with the least valued items.

The three most valued activities were Explaining by the teacher, Knowing the times tables and Understanding why my solution is incorrect or correct. Explanations by the teacher can be understood as trusting authorities for providing knowledge, but it can also be understood as a righteous demand for access to knowledge and understanding. The other two both refers to correctness, where the third item also stresses the understanding of why. We noted a strong similarity between the responses from all the 743 students, in other words both year 5 and the year 8 students responded 


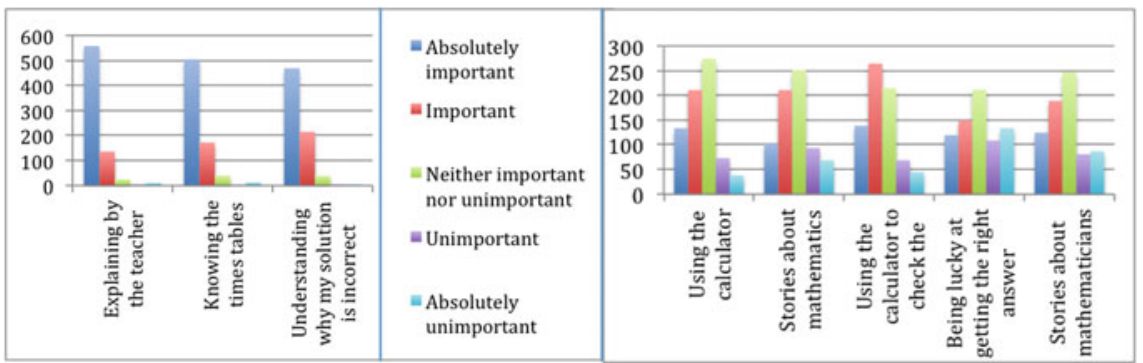

Fig. 5.1 The diagram displays the number of students (among the 742 respondents) responding to each alternative on top three most important items and bottom five least important items

in the same way and valued the same activities in the top three group. Only 16 respondents in the whole cohort marked "knowing the times tables" as less important.

Among the least valued items, there is a large spread in students' responses. So, rather than being valued as not important, we observed a large individual variance in the importance students attribute to those items. Being at the bottom of the list of valued items here means that an item is still important for many students, however, due to the large spread, we cannot see these items as representing shared valuing. The stories about mathematics or mathematicians were mostly neutrally valued, and might not be familiar for all students. Several students in the pilot test would express that luck has nothing to do with mathematics, this was the one question they would react to spontaneously. Activities including use of the calculator were also to a large extent neutrally valued.

Summing up, the most valued items reflects a valuing of a correct explanation/knowledge or understanding, whereas the least valued items has to do with the calculator or the history of mathematics. In addition, most students find that being lucky at getting the right answer has nothing to do with learning mathematics. We notice that the most valued items are quite common in Swedish mathematics classrooms, whereas the least valued are not.

\subsection{Discussion}

At the departure of this project we were hoping to learn about possibilities to align mathematics teaching with students' valuing of activities for learning, in line with the curricular intentions of democratic participation and actions. However, we arrived at the somewhat discouraging result, that students' valuing of "knowing the times tables" and "teachers' explanations" and "correctness" over explorative, communicational and collaborative activities. We asked ourselves what might be the cultural and historical reasons behind these results. 
Mathematics teaching does not exist in a vacuum. It is affected by, and at the same time affects cultural expressions, within the mathematics classroom as well as outside. For example, the Swedish children books and films about Pippi Longstocking, may serve as an illustrative example. Pippi, an orphaned eleven-years old strong, kind but also a stubborn and questioning girl, lives on her own with a horse and a monkey. In one episode, her two very well-behaving friends Tommy and Annika tell her that she needs to attend school. This scene describes the very first and only time Pippi ever enters a classroom:

"Hey, everybody," hollered Pippi, swinging her big hat. "Am I in time for pluttification?" (Lindgren 1945, 2007, p. 60).

'Pluttification' tables, or the multiplication tables, as a properly fostered Swedish student knows to name them, are in our results one of the most important activities in mathematics classrooms as seen by students. Even though Pippi is a children's book fiction she captures well the importance assigned to the times tables, as that is the only thing she knows about school. This fiction is still relevant for Swedish children, who share the valuing of times tables as an important part of school.

Lundin (2008) reminds us that when schooling in Sweden became public and mandatory, teachers had to deal with a larger number of first generation children attending school. The first mathematics textbooks, published in the early 1940s aimed to both support mathematics learning and to support teachers in coping with disciplinary problems. "This need led to the promotion of schoolbooks filled with a large number of relatively simple mathematical problems, arranged in such a way that they (ideally) could keep any student, regardless of ability, busy — and thus quiet - for any time span necessary" (p. 376). The teaching at that time hence became a medium for both mathematics learning and fostering children. We remind ourselves that this is the kind of enculturated teaching practice todays students' parents and grandparents experienced. We do not see our results as a reflection of the most common teaching, nor as the most important means for learning mathematics. Instead, we must understand the valuing of times tables or teachers' explanations as an expression of enculturated and therefore culturally valued actions in mathematics classrooms, where this enculturation takes place not only in school, but in conversations with parents, grandparents, in media and in children's books.

At a policy level, different actions are valued. Two recent and important School Inspectorate's research reports concerning primary and secondary school education respectively (School Inspectorate 2009, 2010) concluded that teachers to a large extent rely on textbooks when planning their teaching, hence they trust the textbooks to fulfil curricular objectives. The Inspectorate highlighted the fact that students' individual work still dominates mathematics lessons, thus resulting in mainly mechanical calculations with less time for students' discussions, collaborations and problem solving. Teaching seems to result in under-stimulated students, who experience mathematics as a boring, tedious and sometimes even "stupidizing" [fördummande] subject (School Inspectorate 2010, p. 8). To take this argument one step further, we note that such "stupidizing" activities do not rhyme with the Swedish educational values, based on the declaration of Human Rights (United Nations 1948), stating 
humans as endowed with reasoning, and that this reasoning should be protected by democracy, and at the same time generate democracy through democratic actions.

Researchers and School inspections has been looking at the rationale or consequences from this particular way of organising mathematics education, with a teaching mainly based on individual student (textbook) work. It is still found to support teachers in managing non-homogeneous student groups, however now with the argument that each student shall be able to work according to his/her previous learning and needs (Johansson 2006). The argument is that this is how democratic participation and inclusion is fulfilled (Hansson 2010; Lingefjärd and Meier 2010). Lundin's (2008) explanation of the historical development resonates with the phenomena described by the School Inspectorate $(2009,2010)$ although the reasons are different. We add that the particular learning activities; as knowing the times tables and teacher's explanations, are the most valued activities by students. And they were clearly conflicting with the intentions formulated in the steering documents. It is precisely here we find a conflicting valuing and maybe one possible explanation to why the desired transformation of mathematics teaching takes time (Seah et al. 2016). Following this argument, we now discuss how the survey results may be used to better understand why teaching transformation seems so difficult in the mathematics classroom.

In our results, students valued "teacher explaining" as important. We may understand this response as students appreciating good explanations or scaffolding by teachers, or even a special relationship with the teacher. However, it also recognises that the mathematical learning activities are the responsibility of the teachers. This may cause valuing-conflicts, when teachers apply intentions in the curriculum, stating that teachers' starting point shall be "ensuring that all pupils can exercise real influence over working methods, forms and contents" and that "pupils are able and willing to take personal responsibility for their learning" (Skolverket 2011, p.17). Students' valuing of "teacher explaining" reflects an understanding of the learning of mathematics as the responsibility of teachers, rather than as a result of "joint labour" (Radford and Roth 2011) or as an individual democratic responsibility.

The political aim to allow space for students' influence on the planning and evaluation of mathematics teaching, can be expected to align well with the mathematical values openness, rationality and progress where perhaps openness is the most important of the three. Thus, to what extent do mathematics lend itself to such negotiation? Very little, according to Wagner and Herbel-Eisenman (2013, p. 483). They demonstrate the very central authoritative nature of mathematics through its "interest in certainty". In this way mathematics is epistemologically different from other subjects in school, since deductive reasoning based on already stated axioms, rather than empirical explanations and students' own initiatives, are valued. The survey results indicate precisely that students value control through certainty and the mastery of rules. Thereby, arriving at students' influence on their learning and planning of mathematical activities may be specifically challenging in mathematics.

We argue that the contradiction between the political expectations of democratic participation and actions, and the invitation to students to influence teaching on the one hand, and on the other hand students use of this influence through valuing teacher 
explaining, mastering times tables and understanding why the answer is incorrect, rather conserve a mathematics teaching organised around values as objectism and control than through openness and rationalism. Thus, giving back the influence to the historically supported way of learning mathematics, to the teacher who passes on to the textbooks.

This may explain the dilemma teachers face when opening up spaces for students to influence the classroom work. Aligning teaching with what Swedish students' value involves a risk to conserve a traditional way of mathematics teaching, or in Skolverket's (2011) words, an "exercise learning paradigm”. This result also highlights that implementing a more democratic mathematics teaching and applying open learning activities that challenges students valuing may be a long process, where consistent values need to be negotiated and addressed throughout the process: from the planning to the assessment of mathematics knowledge in line with the student Zissy's comment above.

Acknowledgements We are grateful for critical conversations with Prof. Em. Alan Bishop, Prof. Em. Philip Clarkson and Assoc. Prof. W. T. Seah and with dear colleagues at Stockholm University: Anette de Ron and Elisabeth Hector.

\section{References}

Aguilar, M. S., \& Zavaleta, J. G. M. (2012). On the links between mathematics education and democracy: A literature review. Pythagoras, 33(2).

Alvestad, M. \& Samuelsson, I. (1999). A comparison of the national preschool curricula in Norway and Sweden. Early Childhood Research and Practice, 1(2). Retrieved from http://ecrp.uiuc.edu/ v1n2/alvestad.html.

Andersson, A. (2011). A "Curling Teacher" in Mathematics Education: Teacher identities and pedagogy development. Mathematics Education Research Journal, 23(4), 437-454.

Andersson, A., \& Österling, L. (2013). Measuring immeasurable values. In A. M. Lindmeier, \& A. Heinze (Eds.), Proceedings of the 37th Conference of the International Group for the Psychology of Mathematics Education (Vol. 2, pp. 17-24). Kiel: PME.

Andersson, A., \& Österling, L. (2014). Metric equivalence in international surveys: Cultural edges. In Liljedahl, P., Nicol, C., Oesterle, S., \& Allan, D. (Eds.). Proceedings of the Joint Meeting of $P M E 38$ and PME-NA 36 (Vol. 1). Vancouver, Canada: PME.

Andersson, A., \& Valero, P. (2015). Negotiating critical pedagogical discourses: Contexts, mathematics and agency. In P. Ernest \& B. Sriraman (Eds.), Critical mathematics education: Theory, praxis and reality (pp. 203-228). Charlotte, USA: Information Age Publishing.

Andersson, A., \& Wagner, D. (2017). Love and bullying in mathematical conversations. In Chronaki, A. (Ed.). Proceedings of the 9th International Mathematics Education and Society Conference (pp. 382-392). Volos, Greece: University of Thessaly Press.

Andersson, A., \& Wagner, D. (2018). Re-mythologizing mystery in mathematics: Teaching for open landscapes versus concealment. Education Sciences, 8, 41; https://doi.org/10.3390.

Baba, T., Iwasaki, H., Ueda, A., \& Date, F. (2012). Values in Japanese mathematics education: Their historical development. ZDM Mathematics Education, 44(1), 21-32.

Biesta, G. J. J. (2007). Education and the democratic person: Towards a political conception of democratic education. Teachers College Record, 109(3), 740-769. 
Biesta, G. J. J. (2009). Good education in an age of measurement: on the need to reconnect with the question of purpose in education. Educational Assessment, Evaluation and Accountability, 21(1), 33-46.

Bishop, A. (1988). Mathematical enculturation: A cultural perspective on mathematics education. Dordrecht: Kluwer Academic Publishers.

Bishop, A. (2002). Mathematical acculturation, cultural conflicts, and transition. In G. De Abreau Bishop, A., \& N. Presmeg (Eds.), Transitions between contexts of mathematical practices (pp. 193-212). Netherlands: Springer.

DeJarnette, A. F., \& González, G. (2015). Positioning during group work on a novel task in Algebra II. Journal For Research In Mathematics Education, 46(4), 378-422.

Einarsdottir, J., Purola, A. M., Johansson, E. M., Broström, S., \& Emilson, A. (2015). Democracy, caring and competence: Values perspectives in ECEC curricula in the Nordic countries. International Journal of Early Years Education, 23(1), 97-114.

Esmonde, I. (2009). Mathematics learning in groups: Analyzing equity in two cooperative activity structures. The Journal of the Learning Sciences, 18(2), 247-284.

Hansson, Å. (2010). Instructional responsibility in mathematics education: modelling classroom teaching using Swedish data. Educational Studies in Mathematics, 75(2), 171-189.

Hofstede, G., Hofstede, G. J., \& Minkov, M. (2010). Cultures and organizations: software of the mind: Intercultural cooperation and its importance for survival (3rd ed.). New York: McGrawHill.

Johansson, M. (2006). Teaching mathematics with textbooks: A classroom and curricular perspective. Doctoral Thesis. Luleå: Luleå tekniska universitet.

Kurth, L. A., Anderson, C. W., \& Palincsar, A. S. (2002). The case of Carla: Dilemmas of helping all students to understand science. Science Education, 86(3), 287-313.

Lindgren, A. (2007). Pippi Longstocking. London: Penguin Books Limited.

Lingefjard, T., \& Meier, S. (2010). Teachers as managers of the modelling process. Mathematics Education Research Journal, 22(2), 92-107.

Lundin, S. (2008). Skolans matematik: en kritisk analys av den svenska skolmatematikens förhistoria, uppkomst och utveckling. Doctoral Thesis. Uppsala: Acta Universitatis Upsalensis.

Ministry of Education [Utbildningsdepartementet] (2011). SFS2010:800, Skollagen, 1 kap \$4-5. Stockholm: Riksdagen.

Norén, E. (2015). Agency and positioning in a multilingual mathematics classroom. Educational Studies in Mathematics, 89(2), 167-184.

OECD. (2006). Starting strong II: Early childhood education and care. Paris: OECD.

Radford, L., \& Roth, W. M. (2011). Intercorporeality and ethical commitment: An activity perspective on classroom interaction. Educational Studies in Mathematics, 77(2-3), 227-245.

School Inspectorate. (2009). Skolinspektionens Kvalitetsgranskning, Undervisningen i matematik-utbildningens innehåll och ändamålsenlighet. Rapport 2009:5. Stockholm: Frizes.

School Inspectorate. (2010). Olika elever-samma undervisning. Skolinspektionens erfarenheter och resultat från tillsyn och kvalitetsgranskning 2010. 2011:4396. Stockholm: Frizes.

Seah, W. T. (2013). Assessing values in mathematics education. In A. M. Lindmeier \& A. Heinze (Eds.), Proceedings of the 37th Conference of the International Group for the Psychology of Mathematics Education (Vol. 4, pp. 193-200). Kiel, Germany: PME.

Seah, W. T., \& Andersson, A. (2015). Valuing diversity in mathematics pedagogy through the volitional nature and alignment of values. In A. Bishop, H. Tan, \& T. Barkatsas (Eds.), Diversity in mathematics education: Towards inclusive practices (pp. 167-184). Switzerland: Springer.

Seah, W. T., Andersson, A., Bishop, A., \& Clarkson, P. (2016). What would the mathematics curriculum look like if values were the focus? For the Learning of Mathematics, 36, 1.

Skovsmose, O. (2005). Travelling through education: Uncertainty, mathematics, responsibility. Rotterdam: Sense Publishers.

Skolverket, (2011). Curriculum for the compulsory school, preschool class and the recreation center. Stockholm: Skolverket. 
Stemhagen, K. (2016). Deweyan democratic agency and school math: Beyond constructivism and critique. Educational Theory, 66(1-2), 95-109.

Survey Research Center. (2010). Guidelines for best practice in cross-cultural surveys. In J. Harkness (Ed.). Retrieved January 09, 2013, from Institute for Social Research, University of Michigan, A. Arbour. http://www.ccsg.isr.umich.edu/.

Swedish Research Council [Vetenskapsrådet] (2011). Good research practice. [God forskningssed]. Stockholm: Vetenskapsrådet.

Swan, M. (2014). Improving the alignment between values, principles and classroom realities. In Y. Li \& G. Lappan (Eds.), Mathematics curriculum in school education (pp. 621-636). Netherlands: Springer.

United Nations. (1948). General Assembly Resolution 217 (III). Paris: United Nations Official Documents.

United Nations (2016). Global issues. Democracy. Retrieved September 252016 from http://www. un.org/en/globalissues/democracy/.

Wagner, D., \& Herbel-Eisenmann, B. (2009). Re-mythologizing mathematics through attention to classroom positioning. Educational Studies in Mathematics, 72(1), 1-15.

Wagner, D., \& Herbel-Eisenman, B. (2013). Disbursing authority among mathematics students. Proceedings of the Seventh International Mathematics Education and Society Conference (pp. 483-492). Cape Town: MES7.

Wagner, D., \& Herbel-Eisenmann, B. (2014). Identifying authority structures in mathematics classroom discourse: A case of a teacher's early experience in a new context. ZDM: The International Journal of Mathematics Education, 46(6), 871-882.

Wood, M. B. (2013). Mathematical micro-identities: Moment-to-moment positioning and learning in a fourth-grade classroom. Journal for Research in Mathematics Education, 44(5), 775-808.

Open Access This chapter is licensed under the terms of the Creative Commons Attribution 4.0 International License (http://creativecommons.org/licenses/by/4.0/), which permits use, sharing, adaptation, distribution and reproduction in any medium or format, as long as you give appropriate credit to the original author(s) and the source, provide a link to the Creative Commons license and indicate if changes were made.

The images or other third party material in this chapter are included in the chapter's Creative Commons license, unless indicated otherwise in a credit line to the material. If material is not included in the chapter's Creative Commons license and your intended use is not permitted by statutory regulation or exceeds the permitted use, you will need to obtain permission directly from the copyright holder.

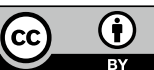

